\title{
Práticas de Linguagem na Amazônia Paraense
}

\section{Language Practices in the Paraense Amazon}

Carlos Antônio de Andrade Silva ${ }^{\mathrm{a}}$; Miranilde Oliveira Neves ${ }^{\mathrm{a}}$

anstituto Federal de Educação, Ciência e Tecnologia do Pará. PA, Brasil

*E-mail: miranilde.oliveira@ifpa.edu.br

\begin{abstract}
Resumo
Esta pesquisa apresenta a visão de estudantes, professores e coordenação sobre as práticas de linguagens de estudantes da Amazônia Paraense em cursos técnicos integrados ao Ensino Médio, a partir da Pedagogia da alternância. Os estudantes têm aulas em um período acadêmico e em outro período retornam às suas residências interioranas para unir os conhecimentos recebidos na escola, às práticas laborais de onde vivem. Esta investigação versa sobre jovens e adultos de cinco municípios paraenses: Abaetetuba, Castanhal, Magalhães Barata, Santa Isabel e São Domingos do Capim, que trabalham na cadeia produtiva da agricultura familiar, em especial, na produção de açaí, farinha, pesca, pecuária para corte e produção de leite. São estudantes do Curso de Agropecuária do PROEJA - Programa Nacional de Integração da Educação Profissional com a Educação Básica na Modalidade de Educação de Jovens e Adultos. Pretende-se demonstrar neste estudo, a construção dos letramentos durante este ensino. Selecionou-se autores que investigam pedagogia da alternância, educação do campo e letramentos para respaldar a parte teórica da pesquisa. Optou-se pela metodologia quali-quantitativa, na modalidade de estudo de caso e com a aplicação de questionários semiestruturados e análise documental. Os resultados obtidos revelaram que os professores trabalham os letramentos, entretanto, as práticas pedagógicas nem sempre acontecem de forma dialógica ao contexto sociocultural e laboral dos estudantes. Ao final da pesquisa, foi evidenciado que as práticas de letramentos devem ser pensadas para o desenvolvimento social, político e econômico dos estudantes em um ambiente que interligue os conhecimentos prévios dos estudantes a essas práticas.
\end{abstract}

Palavras-chave: Linguagens. Pedagogia da Alternância. PROEJA.

\begin{abstract}
This research present the students, teachers and coordination view on the language practices of students from the Paraense Amazon in technical courses integrated to High School, from the Pedagogy of alternation: students have classes in one academic period and in another period they return to their rural residences to combine the knowledge received at school, with the work practices where they live. This research is about young people and adults from five cities in Pará: Abaetetuba, Castanhal, Magalhães Barata, Santa Isabel and São Domingos do Capim, who work in the family agriculture production chain, especially in the production of açai, flour, fishing, livestock for cutting and milk production. They are students of the Agricultural Course of PROEJA - National Program for the Integration of Professional Education with Basic Education in the Modality of Education of Youth and Adults. It is intended to demonstrate in this study, the construction of literacies during this teaching. Authors were selected who investigate alternation pedagogy, rural education and literacies to support the theoretical part of the research. We opted for the qualitative and quantitative methodology, in the case study modality and with the application of semi-structured questionnaires and documentary analysis. The results obtained revealed that the teachers work the literacies, however, the pedagogical practices do not always happen in a dialogical way to the students'socio-cultural and work context. At the end of the research, it was evidenced that literacy practices should be designed for the social, political and economic development of students in an environment that links students' prior knowledge to these practices.
\end{abstract}

Keywords: Languages, Alternation Pedagogy, PROEJA.

\section{Introdução}

Em termos de linguagens e de beleza natural, pode-se considerar a Amazônia Brasileira - em toda a sua extensão - um local rico de onde emanam termos, expressões e uma cultura peculiar, pois se difere da de outros locais no que se refere a variedades linguísticas específicas que só são encontradas no contexto amazônico. As metodologias também se diferem, em relação à grande parte do país. É o caso da Pedagogia da alternância: os estudantes têm aulas em um período acadêmico e em outro período retornam às suas residências em área camponesa para unir os conhecimentos recebidos na escola às práticas laborais de onde vivem. Aqui serão ressaltadas as contribuições da pedagogia da alternância na formação desses estudantes, os quais são jovens e adultos de cinco municípios paraenses: Abaetetuba, Castanhal, Magalhães Barata, Santa Isabel e São Domingos do Capim.

O ensino, nas últimas décadas, tem se tornado motivante devido às diversas ferramentas didáticas, à evolução da tecnologia e às oportunidades de acesso a conteúdos, mas ao mesmo tempo, é um cenário também preocupante. Por quê? Porque o estudante espera uma aula estimulante, espera 
aprender algo novo e mais que isso: unir seus conhecimentos de sala de aula, àqueles já obtidos e aos que vão se configurando em seu ambiente social, cultural e laboral e diante disso, o professor necessita de uma preparação constante e uma visão sistêmica dessa demanda. Esta é a realidade e um dos desafios do Programa Nacional de Integração da Educação Profissional com a Educação Básica na Modalidade de Educação de Jovens e Adultos - PROEJA - investigado neste estudo, pois conseguir unir a teoria do tempo escola ao tempo na comunidade e ao final, contextualizar tudo isso, nas avaliações das matrizes curriculares do curso, neste caso, o curso técnico em Agropecuária, é uma questão desafiadora.

A educação do campo tem recebido enfoque, em alguns trabalhos acadêmicos, nas últimas décadas, e merece esse espaço, pois foi renegada durante muito tempo e ainda hoje possui desafios constantes, seja em termos de legalização das lutas, em geral, conseguidas a partir de movimentos sociais, seja no enfrentamento à perda de direitos já alcançados, como é o caso do programa de formação Pronera - que durante muito tempo, contribuiu para formar cidadãos do ensino fundamental a especializações e há cerca de um ano, exatamente no dia 20 de fevereiro de 2020 foi extinto pelo Decreto 10.252.

A luta dos povos do campo é intensa. Vivemos entre pedras e rios - mas pedras que nos firmam e rios caudalosos que banham nossas linguagens e a nossa cultura amazônica tão específica e singular. Centenas de línguas já se perderam nesses rios, mas na luta pela formação de qualidade, é preciso manter a defesa por práticas de letramentos que ressaltem o valor e os saberes dos nossos ribeirinhos - que uma vez por ano, mergulham na famosa pororoca de São Domingos do Capim; no rio Pará que banha Abaetetuba, nos castanhais que enriquecem Castanhal, na marcante Mata Atlântica em Santa Isabel e nos singulares saberes de pescadores e agricultores de Magalhães Barata - alguns desses - estudantes investigados neste trabalho.

O objetivo da pesquisa foi verificar como está a ocorrer o processo de construção dos letramentos do campo nas aulas de linguagens, ministradas por professores especificamente de Redação, Língua Portuguesa, Literatura, Língua Inglesa e Língua Espanhola em um Instituto Federal de Educação do Norte do Brasil. Integrar, portanto, a realidade local às aulas de linguagens é algo que merece ser levado em consideração nas reflexões sobre o ensino e a aprendizagem.

\section{Material e Métodos}

Para se alcançar os resultados da pesquisa foram seguidos os passos descritos a seguir, a partir da descrição da problemática em evidência - as dificuldades dos estudantes quando expostos às questões de letramentos nas aulas de linguagens e à ausência de valorização dos aspectos culturais e laborais da agricultura familiar no processo de ensinoaprendizagem e sua relação com a Pedagogia da alternância. A partir desta problemática, descreve-se o público alvo da pesquisa, os procedimentos metodológicos adotados, a escolha do referencial teórico e como foram alcançados os resultados.

\subsection{Participantes da Pesquisa}

Os Participantes da pesquisa foram: a) Professores de Linguagens (Português, Redação, Literatura, Inglês e Espanhol) de um Campus Federal do Norte do Brasil. Estes lecionaram no $2^{\circ}$ e $3^{\circ}$ ano PROEJA 2019; b) Coordenador do Programa Nacional de Integração da Educação Profissional com a Educação Básica na Modalidade de Educação de Jovens e Adultos-PROEJA do Campus pesquisado; C) Estudantes do $2^{\circ}$ ano A PROEJA (iniciou em 2018) e; d) Estudantes do $3^{\circ}$ ano D PROEJA (iniciou em 2017).

A turma do $2^{\circ}$ ano A PROEJA (2018) é composta por 22 jovens e adultos, enquanto a turma do $3^{\circ}$ ano D PROEJA (2017) é composta por 20 jovens e adultos que trabalham na cadeia produtiva da agricultura familiar, nas seguintes atividades: produção de açaí, farinha, pesca, pecuária para corte, produção de leite, dentre outras. atividades agrícolas que garantem processos de transformações de práticas concretas de cidadania, as quais precisam ser integradas ao processo de ensino-aprendizagem, visando ao fortalecimento da agricultura familiar.

Sabendo que mais de $60 \%$ dos estudantes do PROEJA participantes da pesquisa, residem nas cidades de Abaetetuba, Castanhal, Magalhães Barata, Santa Isabel e São Domingos do Capim, e que os demais municípios estão fora do campo de abrangência territorial que o Campus passou a atender a partir de 2017, a pesquisa de campo foi realizada nas cidades supracitadas.

\subsection{Procedimentos Metodológicos}

A presente investigação baseou-se em uma abordagem quali-quantitativa, uma vez que se preocupou em sistematizar dados estatísticos com dados qualitativos obtidos de forma simultânea. O que para Knechtel (2014) possibilita correlacionar a interpretação de informações quantitativas e qualitativas, pois além de se preocupar com o dado imediato, quantificado, aprofunda-se nas informações de forma que traz outros dados, que estão além do conhecimento imediato.

O levantamento de dados ocorreu em três momentos: inicialmente, por meio da revisão bibliográfica sobre os temas-chave (PROEJA, Educação do Campo, letramentos, Cultura e trabalho) e revisão Documental (Projeto Pedagógico do Curso do PROEJA do IFPA do Campus investigado); posteriormente por dois questionários semiestruturados destinados aos professores de linguagens e coordenador do curso do PROEJA do IFPA do Campus pesquisado, para que a partir da leitura e análise destes, passasse-se ao terceiro momento da pesquisa, que se caracterizou pela história de vida e questionário semiestruturado aplicado aos estudantes.

A partir dos estudos que foram desenvolvidos com 
as coletas de dados (pesquisa de campo, bibliográfica e documental) foi possível traçar um perfil sociocultural e laboral dos estudantes de Abaetetuba, Castanhal, Magalhães Barata, Santa Isabel e São Domingos do Capim, cidades das quais mais de $50 \%$ dos estudantes do PROEJA vivem. Tal perfil serviu de guia para que os professores (principalmente os de linguagens) identificassem os sujeitos do campo e os contextualizassem nos seus planos de ensino, incorporando a realidade supracitada às práxis do ensino/aprendizagem dos letramentos.

Em relação aos questionários, todos foram respondidos on-line por meio da ferramenta Google formulários que possibilitou a difusão dos questionários aos professores, coordenador e estudantes, no caso desses últimos, foram conduzidos ao laboratório de informática do Campus analisado, onde os pesquisadores explicaram e apresentaram a proposta e objetivos da pesquisa.

Os questionários, com onze questões destinadas aos discentes, oito questões aos professores e oito destinadas à coordenação do Curso, tiveram o objetivo de descobrir se os estudantes costumavam fazer atividades laborais no campo, se os professores das disciplinas básicas e técnicas desenvolviam atividades que valorizassem suas comunidades ou tinham um ensino descontextualizado, quais as suas principais dificuldades nas aulas de linguagens, o que compreendiam por gênero textual, dentre outros fatores importantes para a análise.

Em relação aos professores, os questionários focaram em especial, na aprendizagem dos letramentos e como eles são enfatizados em sala de aula, quais as principais dificuldades apresentadas pelos estudantes nas aulas de linguagens, como definem a pedagogia da alternância, dentre outras questões. A coordenação não poderia ficar à parte da pesquisa, assim, foi necessário saber do atual coordenador, na época, se estava a ocorrer ou se em algum outro momento aconteceram formações continuadas aos professores do PROEJA, o que ele ponderava sobre a pedagogia da alternância e em que pontos, como coordenador poderia contribuir nesse processo de formação discente.

$\mathrm{O}$ trabalho de campo com os estudantes foi realizado em dois momentos: inicialmente, com um questionário aplicado aos estudantes do $2^{\circ} \mathrm{A} \mathrm{e} 3^{\circ} \mathrm{D}$ PROEJA e posteriormente, com a observação in loco nas comunidades nas quais residem mais de $50 \%$ dos estudantes das duas turmas: Abaetetuba, Castanhal, Magalhães Barata, Santa Isabel e São Domingos do Capim.

Os resultados da pesquisa foram catalogados a partir das análises de conteúdo (Bardin, 2011), as quais foram problematizadas nos questionários semiestruturadas $\mathrm{e}$ observação do cotidiano sociocultural e laboral dos estudantes norteados pela revisão bibliográfica e documental, com destaque para as dificuldades dos estudantes quando expostos às questões de letramentos nas aulas de linguagens e a ausência de valorização dos aspectos culturais e laborais da agricultura familiar no processo de ensino-aprendizagem.

Para melhor organização dos dados, optou-se por fazer uma breve codificação dos grupos participantes, conforme quadro abaixo:

Quadro 1 - Lista de códigos dos questionários

\begin{tabular}{|l|c|}
\hline \multicolumn{1}{|c|}{ Entrevistados } & Código \\
\hline Discentes do PROEJA do IFPA (Agropecuária) & DP \\
\hline $\begin{array}{l}\text { Professores de Linguagens do PROEJA do IFPA } \\
\text { (Agropecuária) }\end{array}$ & PLP \\
\hline Coordenador do PROEJA do IFPA (Agropecuária) & CP \\
\hline
\end{tabular}

Fonte: Dados da pesquisa.

A análise dos dados seguiu uma organização prévia que estabelece categorias e dimensões que variam de acordo com o objetivo de cada questionário. Primeiramente, foi feita uma análise das informações obtidas com o corpo discente do PROEJA (DP); posteriormente, foram analisadas as falas dos professores de Linguagens do PROEJA (PLP), e por fim, as respostas do coordenador do PROEJA (CP).

\section{Resultados e Discussão}

A partir das análises de conteúdo problematizadas nos questionários semiestruturados e da observação do cotidiano sociocultural e laboral dos estudantes norteada pela revisão bibliográfica, buscou-se identificar as dificuldades dos estudantes quando expostos às questões de letramentos nas aulas de linguagens, mediadas pela pedagogia da alternância. Sendo assim, analisa-se nesse espaço, as respostas dos discentes, dos docentes e da coordenação do curso pesquisado.

A pesquisa demonstrou que dos quarenta e dois estudantes matriculados nas turmas do $2^{\circ} \mathrm{A}$ e $3^{\circ}$ D PROEJA em 2019, trinta e oito responderam ao questionário, totalizando $90,1 \%$ da amostra, sendo $63,2 \%$ homens e $36,8 \%$ mulheres entre vinte e quarenta anos.

O questionário semiestruturado aplicado ao alunado teve por objetivo descobrir as principais dificuldades de aprendizagem dos letramentos nas aulas de linguagens. Ele foi composto por 11 perguntas. No recorte feito neste artigo será apresentado um resultado geral, após a leitura de todas as respostas obtidas.

A partir da coleta dos dados foi possível traçar um perfil predominante dos estudantes do PROEJA: a maioria tinha concluído o Ensino Médio ou estava em processo de conclusão, mas eles decidiram voltar para o início do Ensino Médio, porque esse se integra à formação técnica em Agropecuária, a qual pode ser aplicada à agricultura familiar, produzida em suas próprias casas, à comunidade na qual vivem ou a empresas de um modo geral, o que para eles será responsável pelo acesso ao mercado de trabalho e à evolução socioeconômica pessoal e da região onde vivem.

Dos 38 estudantes entrevistados, 26 estavam sem estudar há pelo menos um ano, oito estavam cursando o Ensino Médio, mas o interromperam para estudar no PROEJA do Campus investigado de forma integrada ao Técnico; três tinham 
acabado de concluir o Ensino Médio; um não respondeu à pergunta de forma que fosse disponibilizada esta informação.

Para descobrir como as práticas de letramentos estão a ser construídas, questionou-se também dos estudantes sobre a noção prévia que tinham de tipologia e gênero textual, uma vez que são conteúdos indispensáveis a uma formação significativa, pois são conhecimentos inerentes à língua, que se aplicam em diversas manifestações da oralidade e da escrita.

Com base em Bakhtin (1997) e Bronckart (1999), compreende-se que a língua é considerada como uma forma de ação social e histórica que diz e constitui a realidade. Com isso, toda a postura teórica que aqui se apresenta, se insere nos quadros da hipótese sócio-interativa da língua. É neste contexto, que os gêneros textuais se constituem como ações sócio-discursivas capazes de agir e dizer sobre o mundo, e assim, de algum modo o constituir. Compreender as distinções entre gêneros e tipos textuais é importante, pois a partir dessas definições, ficará mais acessível ao estudante o seu conhecimento nas questões que lidam com a interpretação de textos, dentre outras questões de linguagens.

Foi constatado que $47,4 \%$ dos estudantes entrevistados afirmam que em seu cotidiano sociocultural e laboral ocorre a produção e/ou consulta de gêneros textuais. Observou-se, a partir das respostas, que há uma interação com os gêneros textuais da escrita no cotidiano do alunado, mesmo que eles identifiquem isso ou não, pois são produtores e consumidores dos mais diversos gêneros textuais da escrita existentes, o que mostra a importância de se trazer os gêneros textuais do cotidiano dos estudantes para a sala de aula como forma de os empoderar como leitores e produtores textuais ativos e atuantes na construção e reconstrução dos mais diversos gêneros textuais da escrita e oralidade existentes.

Sobre as impressões dos estudantes a respeito da importância de incorporar as questões socioculturais e laborais à realidade escolar, cerca de 94,7\% reconhecem essa importância, o que é coerente para a aprendizagem que o professor almeja ver em sua classe.

A efetivação de uma educação de qualidade, pensada para o desenvolvimento social, político e econômico da população do campo se dá por meio de um ambiente que interligue os conhecimentos prévios dos estudantes: cultura, trabalho e interesses da agricultura camponesa ao processo de ensino aprendizagem, a fim de gerar conhecimentos e tecnologias transformacionais (ARROYO; FERNANDES,1999).

Em relação às dificuldades de aprendizagem, todos os trinta e oito estudantes responderam à pergunta e relataram que as principais dificuldades de aprendizagem estão relacionas às disciplinas de Língua Portuguesa e Redação, principalmente, quando correlatas às regras da gramática normativa e à interpretação e produção textual.

Foram também identificadas dificuldades correlatas ao ensino das línguas estrangeiras Inglês e Espanhol, principalmente, nos conteúdos de interpretação, tradução e pronunciação das palavras. Além disso, foram expostos problemas de aprendizagem relacionados ao excesso de disciplinas que os estudantes têm ao longo do tempo que passam dentro da instituição, o fato de terem que estudar tantas disciplinas técnicas e do componente curricular básico ao mesmo tempo, o que se agrava com o excesso de trabalhos extra-classe que os professores passam para os estudantes ainda no tempo escola.

Outras dificuldades apontadas pelos estudantes foram: a falta de compreensão da proposta didática da aula do professor; as dificuldades geradas a partir da alternância pedagógica, as más condições físicas do espaço escolar, dos alojamentos (estes estudantes residem na escola) e falta de pontualidade dos professores.

Em relação aos professores, a pesquisa apontou que todos demonstraram se preocupar com a escolha de gêneros textuais que dialoguem diretamente com a realidade sociocultural dos estudantes, mas não deixa claro de que forma a escolha desses gêneros intervém de forma crítica ao contexto sociocultural dos estudantes do PROEJA.

Os professores relataram algumas de suas dificuldades:

O tempo, para mim, é a principal dificuldade enfrentada pelos alunos e mesmo por nós, professores do Proeja. Não conseguimos desenvolver uma aprendizagem mais significativa com eles devido ao tempo escola extremamente diminuto. Logo, devemos planejar o tempo comunidade. Quando nos damos conta, eles já retornaram às casas... (Professor do PROEJA 05).

Esta resposta condiz com a réplica dada por alguns estudantes, pois critica o tempo escola por ser muito curto, o que faz com que os professores tenham que condensar as suas aulas para que sejam computadas em um pequeno espaço de tempo. Como o aluno passará em média trinta dias no tempo comunidade (período em que os estudantes retornam às suas comunidades para aplicar o que aprenderam teoricamente na escola), também há perda na progressividade dos conteúdos, pois a cada retorno, o professor tem que retomar os assuntos do tempo escola anterior.

Outra dificuldade relatada no desenvolvimento da pedagogia da alternância foi a prática da leitura, da escrita e interpretação. Isso porque as dificuldades de leitura e escrita refletem diretamente na interpretação de textos verbais, por isso se faz necessário que o processo de letramento mantenha um dialogismo com as reais necessidades sociolinguísticas dos estudantes.

A Pedagogia da Alternância se caracteriza como uma proposta de ensino distinta da tradicional, o estudante tornase, por meio dela, protagonista do seu próprio conhecimento. O princípio baseia-se no conhecimento empírico de que a vida ensina mais que a escola, a experiência social e profissional, torna-se ponto de partida no processo de ensino-aprendizagem, pois "o método da alternância se dá por três aspectos: ação, reflexão, ação" (BRAMBATI, 2014, p.07). Desta forma, a teoria é em função de melhorar a qualidade de vida de um 
modo evidente. Essas características do método são descritas por Gimonet (1999, p.44), do seguinte modo: "Alternância de tempo e de local de formação, ou seja, de período em situação socioprofissional e em situação escolar. Significa uma outra maneira de aprender, de se formar, associando teoria e prática, ação e reflexão, o compreender e o aprender dentro de um mesmo processo".

Assim, os saberes tradicionais são de suma importância para o desenvolvimento e aprendizagem dos saberes acadêmicos, pois de forma reflexiva, se mesclam entre si, trazendo aprendizado mútuo, tanto para o educador quando para o educando. $\mathrm{O}$ que permite ao aluno o aprimoramento ou desenvolvimento de técnicas condizentes à sua realidade socioespacial, como recomenda a LDB (Lei 9394/1996) em seu artigo 28: "Na oferta de educação básica para a população rural, os sistemas de ensino promoverão as adaptações necessárias à sua adequação às peculiaridades da vida rural e de cada região" (BRASIL,1996, p.11).

Com base no exposto, entende-se que uma das particularidades da população do campo, citada na lei, refere-se ao uso da língua primeira, pois na escola, consideravelmente, privilegia-se o uso da norma culta em detrimento das demais variantes. Tal situação dificulta o processo de ensinoaprendizagem do português brasileiro em escolas do campo.

Neste sentido, a construção da identidade do sujeito do campo está fortemente ligada às lutas e reivindicações dos movimentos sociais, pois foi por meio da autoafirmação dos traços da identidade campestre que se passou a ser exigido do estado uma educação inclusiva que respeitasse seu espaço cultural, físico e laboral, ancorada nos saberes próprios de cada povo, pensados por estes, para estes e no espaço destes.

Desta forma, procedimentos relacionados à pedagogia da alternância nascem da interação entre instituições de ensino e realidades presentes nas famílias agrícolas; por meio do comprometimento contínuo e participativo com o desenvolvimento sustentável das comunidades, compreendendo e valorizando as práticas sociais de formação.

Para Souza et.al (2001), a construção do conhecimento permeia a teoria e a prática, por meio de atitudes pedagógicas que perpassam pelo educador, o conteúdo e o educando, o que caracteriza a construção do conhecimento como uma integração entre sujeito-objeto-sujeito.

$\mathrm{Na}$ perspectiva da pedagogia da alternância, o processo de ensino e aprendizagem ocorre por meio da interação participativa da família, da escola e da comunidade, visando ao desenvolvimento sustentável local, por meio da articulação entre educadores, estudantes e responsáveis, por meio de desenvolvimento de atividades pedagógicas e agrícolas como princípio educativo.

Outro ponto importante apresentado nos resultados é o que relatou uma professora "O uso da ortografia (Mas/ mais, porquês...), o uso de elementos de coesão, pontuação... Sempre há dificuldade no uso da língua culta.". (Professora do
PROEJA 04). Resposta que condiz com as respostas dadas por estudantes também. Nesse caso, nota-se que a preocupação com as regras da gramática normativa é enaltecida na fala tanto do professor quanto do aluno.

As práticas dos letramentos às quais os estudantes do PROEJA têm acesso são quase sempre mediadas, de forma restrita, pelos livros didáticos. E esses, por serem destinados aos estudantes do ensino regular, não dispõem de características específicas que dialoguem de forma direta com a realidade sociocultural e laboral dos estudantes, além de não disporem de estratégias avaliativas que sanem as lacunas deixadas entre um tempo escola e outro.

Para Tfouni (2010, p. 23), o letramento deve ser compreendido como um processo sócio-histórico, portanto, mais amplo que a alfabetização, uma vez que é responsável pelo desenvolvimento social e econômico das sociedades: "Em termos sociais mais amplos, o letramento é apontado como sendo produto do desenvolvimento do comércio, da diversificação dos meios de produção e da complexidade crescente da agricultura."

No contexto supracitado, o significado de letramento transcende o espaço sala de aula e o processo de alfabetização, alcançando, portanto, processos sociais mais amplos, caracterizados pela autora como causa e consequência do desenvolvimento. Desta forma, entende-se por letramento um conjunto de práticas que envolvem a escrita e a leitura com objetivos específicos e em contextos específicos que vão além da sala de aula. Assim, torna-se letrado aquele que desenvolve habilidades de leitura e de escrita e que sabe aplicá-las à sociedade. O que ratifica Soares (2009) quando diz que alfabetizar não garante a plena formação de sujeitos letrados.

Outra definição, que não foi usada nesta investigação, mas que é comumente dada ao termo letrado, no Brasil, está associada ao conceito de pessoa erudita, versada em letras. Sendo a Pessoa Iletrada, portanto, o antônimo, pessoa não erudita, ou que não possui conhecimentos literários. (SOARES, 2009)

A versão do termo inglês para letramento "literacy", vai muito além da decodificação da escrita em leitura, pois se torna responsável pela produção de desenvolvimento sociocultural para o indivíduo letrado e aos membros de seu grupo social. O que justifica a tradução nas obras de Olson (1997) e Ong (1998) do termo letramento como: Cultura escrita.

Contudo, o termo letramento usado neste estudo, tem a acepção de Kleiman (1995, p. 19) que o define como: "conjunto de práticas sociais que usam a escrita, enquanto sistema simbólico e enquanto tecnologia, em contextos específicos para objetivos específicos". A escolha dessa concepção, deveu-se ao fato de a mesma ser capaz de dialogar de forma mais completa as relações entre letramento e cultura, partindo do surgimento da escrita, até o processo de evolução da sociedade.

Em relação à coordenação, o coordenador justificou 
que já esteve no local de fala dos professores, o que lhe proporcionou experiências diretas com os estudantes e demais profissionais da educação. Neste contexto, acredita-se que neste período pôde identificar as principais necessidades dos professores para garantir uma formação cidadã de qualidade que permita aos estudantes se desenvolverem plenamente como cidadãos e profissionais, além de, a partir do contato direto com os demais professores e profissionais de educação, identificar quais as principais dificuldades encontradas pelos professores ao exercerem suas funções com excelência. A fim de que no atual local de fala possa planejar as ações de forma que o objetivo do PPC (Projeto Pedagógico do Curso) de formar cidadãos aptos ao mercado de trabalho seja alcançado.

O coordenador explicou que não há formação continuada direcionada para os professores do PROEJA, pelo menos não de forma planejada o que permite pressupor que existem lacunas no processo de formação dos estudantes, e nas práxis dos professores, porque não ocorre no planejamento Pedagógico um espaço dialogal que permita repensar a prática docente.

Para a coordenação, a Pedagogia da Alternância corrobora o que dizem Souza et. al (2001), como um processo de ensino/aprendizagem que ocorre por meio da interação participativa da família, da escola e da comunidade, visando ao desenvolvimento sustentável local, por meio da articulação entre educadores, estudantes e responsáveis, por meio da sistematização de atividades pedagógicas e agrícolas como princípio educativo. O coordenador acrescentou à sua resposta uma crítica pontual aos professores (que provavelmente pela falta de formações continuadas) não conhecem a proposta didática que norteia a pedagogia da alternância, confundindo-a com meia formação ou formação a distância.

\section{Conclusão}

Entender o local de fala dos estudantes do PROEJA é o passo inicial para se assegurar o direito à formação destes, pois são jovens e adultos, em situação de vulnerabilidade social que em sua maioria desenvolvem atividades laborais voltadas para a agricultura familiar.

Nesse contexto, a pedagogia da alternância se mostra como opção pertinente a esse tipo de formação, pois por meio de alternâncias pedagógicas os estudantes podem garantir o trabalho em suas comunidades e muitas vezes o sustento próprio e de seus familiares, além de desenvolverem habilidades cognitivas que dialoguem os saberes tradicionais aos científicos, por meio do acesso à formação básica e técnica especializada podem gerar desenvolvimento e progresso para as suas comunidades.

No que se refere aos letramentos, observa-se que estes já são trabalhados pelos professores, entretanto, as práticas pedagógicas nem sempre acontecem de forma dialógica ao contexto sociocultural e laboral dos estudantes, situação que se agrava ainda mais quando os intervalos entre o tempo escola e o tempo comunidade não permite a progressividade de conteúdos mais complexos. O que exige do professor que em sua programação didática planeje suas aulas e sequências didáticas de forma que alguns conteúdos que exigem maior complexidade sejam iniciados e concluídos no mesmo tempo escola.

$\mathrm{O}$ questionário aplicado aos discentes, professores $\mathrm{e}$ coordenador possibilitou levantar dados como, por exemplo, quais as características dos livros didáticos adotados pelo PROEJA do Campus pesquisado e de que forma as práticas de letramentos são mediadas pelos professores durante o tempo o qual os estudantes estão na escola. Assim, evidenciou-se que apenas parte dos professores usam o livro didático porque esse não é apropriado às particularidades do perfil do aluno do PROEJA, muito menos à proposta pedagógica do curso, uma vez que não dialoga com a realidade sociocultural e laboral do território paraense. Neste contexto, quando é usado pelos professores, ocorre de forma limitada e adaptada às peculiaridades da proposta pedagógica do PROEJA, fazendo com que os professores tenham que produzir seus próprios materiais didáticos, seja de forma complementar ao livro didático ou não.

No que diz respeito à avaliação da aprendizagem, a pedagogia da alternância propõe que a realidade e as experiências durante o tempo escola e o tempo comunidade sejam mensurados de forma que os conhecimentos tradicionais sirvam de base para a produção do conhecimento científico, de forma que o aluno se sinta modelador de seu próprio conhecimento, fortalecendo deste modo, a agricultura familiar. Portanto, a partir das reflexões desta pesquisa, se pôde concluir que a avaliação no contexto do PROEJA só ocorre de forma satisfatória quando a construção do conhecimento acontece de forma processual, objetivando educar por meio de um contínuo processo de ações, reflexões e participações.

Quanto às práticas de letramentos, inferiu-se que boa parte dos estudantes não conseguem se enxergar como produtores ou consultores de gêneros textuais, embora estes estejam de forma direta e indiretamente presentes em todas as ações sócio-discursivas desenvolvidas pelo ser humano que vive em sociedade. Deste modo, seja de forma escrita ou oralizada, as práticas de interação social e laboral ocorrem por meio de gêneros textuais e é por isso que as práticas de letramentos devem ser sistematizadas pelos professores de linguagens, partindo pela premissa de que seus estudantes são bons escritores, pois são capazes de se comunicar por meio de diversos gêneros, nos mais variados contextos.

Deste modo, a partir das análises foi possível verificar que quase todos os professores já ensinam os letramentos de forma contextual à realidade sociocultural e laboral dos estudantes, de modo que os processos de mediação do conhecimento e verificação da aprendizagem ocorrem de forma contínua e processual, objetivando educar por meio de um ininterrupto processo de ações, reflexões e participações. 
Em relação à coordenação, a partir das análises, foi possível verificar que embora o coordenador do PROEJA não tenha tido experiências prévias na função de coordenador, suas vivências na função de professor do PROEJA lhe permitiram pontuar reflexões quanto às reais necessidades que os estudantes do PROEJA e professores têm.

Sendo assim, a fala do coordenador permite inferir que as principais dificuldades de aprendizagem em linguagens, que os estudantes têm, estão atreladas à falta ou precário dialogismo entre as práticas linguísticas e as reais aplicabilidades socioculturais e laborais, e também na má condução do ensino, no qual o conteúdo programático deveria dialogar com a proposta da pedagogia da alternância, o que reflete diretamente no processo de aprendizagem. Ainda nesse contexto, observa-se que a falta de formação continuada gera lacunas nas práxis dos professores, quanto às especificidades que a alternância pedagógica pretende atingir.

Assim, para que se alcance excelência na educação, as práticas de letramentos devem ser pensadas para o desenvolvimento social, político e econômico dos estudantes, por meio de um ambiente que interligue os conhecimentos prévios dos estudantes: cultura, trabalho e interesses da agricultura camponesa ao processo de ensino aprendizagem, a fim de gerar desenvolvimento e progresso.

Logo, com base nos resultados obtidos nessa investigação, a qual foi desenvolvida em um Programa de Mestrado Profissional, foi possível produzir um material didático que valorizasse a cultura sociocultural e laboral dos estudantes do Programa Nacional de Integração da Educação Profissional com a Educação Básica na Modalidade de Educação de Jovens e Adultos - PROEJA na sala de aula. O e-book intitulado: Atividades Práticas de Linguagens para o PROEJA teve o objetivo de contribuir com a disponibilização de atividades que possam auxiliar o professor de turmas de PROEJA ou outra modalidade de ensino na abordagem letrada nas aulas de linguagens. Apesar das dificuldades, tenta-se alinhar as práticas de linguagens a questões sociais, culturais e laborais desses estudantes amazônidas.

\section{Referências}

ARROYO, M.G.; FERNANDES, B.M. A educação básica e o movimento social do campo. Brasília: Articulação Nacional Por uma Educação Básica do Campo, 1999.

BAKHTIN, M. Estética da criação verbal. Os gêneros do discurso. São Paulo: Martins Fontes, 1997.

BARDIN, L. Análise de conteúdo. São Paulo: Edições 70, 2011.

BRAMBATI, S.A.C. Proposta pedagógica da Casa Familiar Rural de Amarante. 2014. Analecta, v.13 n.1 p.49-65, 2014

BRASIL. Ministério da Educação. Lei de Diretrizes e Bases da Educação Nacional. Brasília: MEC, 1996.

BRONCKART, J.P. Atividades de linguagem, textos e discursos: por um interacionismo sócio-discursivo. São Paulo: EDUC, 1999.

GIMONET, J-C. Nascimento e desenvolvimento de um movimento educativo: As Casas Familiares Rurais de Educação e de Orientação. In: SEMINÁRIO INTERNACIONAL DA PEDAGOGIA DA ALTERNÂNCIA, 1. 1999, Salvador. Anais. Salvador: União Nacional das Escolas Família Agrícola do Brasil, 1999.

KLEIMAN, A.B. (Org.). Os significados do letramento: uma nova perspectiva sobre a prática social da escrita. Campinas: Mercado de Letras, 1995.

KNECHTEL, M.R. Metodologia da pesquisa em educação: uma abordagem teórico-prática dialogada. Curitiba: Intersaberes, 2014.

OLSON, D.R. Cultura escrita e oralidade. São Paulo: Ática, 1997.

ONG, W.J. Oralidade e cultura escrita: a tecnologização da palavra. Campinas: Papirus, 1998.

SOARES, M. Letramento: um tema em três gêneros. Belo Horizonte: Autêntica, 2009.

SOUZA, A.I. et al. Paulo Freire-Vida e obra. São Paulo: Expressão Popular, 2001. 